\title{
Relation of Personality to Grades and Grading in Undergraduate Peer Review
}

\author{
Jenessa Louise Shaw, Kenneth Cramer
}

Peer reviews offer a unique assessment of post-secondary students' writing, wherein students grade fellow students' (or peers') essay submissions according to a provided rubric. Previous research found that students' personality dimensions were related to the grades that students both gave and received through peer assessment. The present study examined the association between personality factors on grader leniency and grades received during a peer review assignment in an introductory psychology course. Participants completed an online survey to assess academic entitlement, learning/grade orientation, narcissism, and the 5-factorpersonality traits; these were later joined to peer review grades received and given. Results showed that rater leniency was negatively related to learning orientation, conscientiousness, and grade orientation. Moreover, the strongest predictors of grades received included academic entitlement, conscientiousness, and narcissism. Implications of these findings, plus directions for future research, are discussed.

Keywords: peer review, rater leniency, personality, academic achievement

L'évaluation par les pairs constitue un processus exceptionnel d'évaluation de l'écriture d'étudiants de niveau postsecondaire. Des étudiants notent les rédactions de leurs camarades de classe (leurs "pairs》) en utilisant une grille d'évaluation qui leur est fournie. Des recherches ont montré que les aspects de la personnalité des étudiants ont une incidence sur les notes que ceux-ci donnent ou reçoivent. La présente étude examine le lien entre, d'une part, les facteurs liés à la personnalité et, d'autre part, la clémence des évaluateurs et les notes reçues au cours d'une évaluation par les pairs dans un cours d'introduction à la psychologie. Les participants ont rempli un sondage en ligne pour mesurer leurs attentes en matière de notes, leur intérêt pour l'apprentissage ou pour les notes, leur narcissisme et les cinq traits centraux de la personnalité. Les réponses au sondage ont ensuite été combinées aux évaluations par les pairs que les participants ont rendues et reçues. Les résultats montrent que la clémence de l'evaluateur est liée de facon négative à l'intérêt en matière d'apprentissage, au caractère consciencieux et à l'intérêt pour les notes. Qui plus est, les principaux indicateurs des notes reçues comprennent l'attente de recevoir de bonnes notes, le caractère consciencieux et le narcissisme. L'article examine les conséquences de ces résultats et indique la direction à prendre pour des recherches à venir.

Mots clés: évaluation par les pairs, clémence de l'évaluateur, personnalité, rendement universitaire 
$\mathrm{P}$ eer review (Joordens, Paré, \& Collimore, 2014) offers a unique assessment of postsecondary students' writing, wherein students grade their peers' essay submissions according to a provided rubric. This type of assessment is growing in popularity due to the many benefits afforded to both instructors and students. Bloxham and West (2004) found that students believe that peer feedback is easier to understand and provides a better learning opportunity than expert (viz. graduate student or professor) feedback. This assessment also provides students with the opportunity to examine other students' work so as to gain a deeper understanding of concepts through others' perspectives (BoaseJelinek, Parker, \& Herrington 2015; Sims, 1989). Having students thoroughly review their peers' submissions aids in the development of both critical thinking skills (Joordens et al., 2014) and deeper learning (Bostock, 2006). Additionally, the experience of grading peers' assignments may further transmit the importance of attention to assessment criteria (Bloxham \& West, 2004) and thus foster critical assessment skills that transfer to other areas of life and learning (Boase-Jelinek et al., 2015).

In addition to the many benefits to students, peer review allows written assignments in larger classrooms and reduces the burden on graders (both graduate students and instructors). Li et al. (2015) found the correlation between student and expert grades was moderately high $(r=0.63)$; Paré and Joordens (2008) similarly found peer-assessment rendered reasonably comparable grades to those derived by experts, though peers were more lenient. However, the trend in student marking has proven inconsistent across studies, wherein peers sometimes offered grades higher and other times lower when compared to experts (Bostock, 2006). Decades earlier, Guilford (1954) first hypothesized that an individual's tendency to over- or under-rate others' work would be relatively stable across time. Kane et al. (1955) supported this by finding that social workers' rating leniency during performance reviews was relatively consistent across time, format, and the coworker in question.

\section{Personality Relates to Both Grading and Grade Leniency}

Although many factors contribute to an individual's grading leniency, individual differences can explain some of this variance. This relation requires further investigation, though some studies have found significant relations between grade leniency and the big five personality traits (Bernadin, Tyler, \& Villonova, 2009; Birjandi \& Syyari, 2016). In contrast, the role of personality on grades is an area more thoroughly researched. Numerous studies and metaanalyses have investigated the relation between the big five personality traits and academic achievement, finding significant links among most (Poropat, 2009; Richardson, Abraham, \& Bond, 2012).

Conscientiousness, characterized by efficiency, selfdiscipline, reliability, achievement orientation, and diligence (McCrae \& John, 1992) is the strongest predictor of academic achievement among the big five personality factors (Poropat, 2009; Richardson et al., 2012). Conscientious students tend to have higher academic self-efficacy and employ a deep learning approach, attempting to fully understand the course material (Zhang \& Ziegler, 2016). The conscientious show better attendance (Farsides \& Woodfield, 2003), time management skills, effort regulation, and even more sophisticated metacognition (Bidjerano \& Dai, 2007). Moreover, conscientiousness is negatively related to self-handicapping, or behaviors that reduce performance to provide an external cause to attribute failure (Ross, Canada, \& Rausch, 2002). Similarly, conscientiousness is also significantly related to grade leniency, where graders higher in conscientiousness tend to be less lenient and give lower grades (Bernadin et al., 2009; Birjandi \& Syyari, 2016). This may be because of the relationship between conscientiousness and academic achievement. The deeper understanding of concepts associated with high scores on this trait (Zhang \& Ziegler, 2016) may lead to an ability to judge the accuracy of assignment content more easily. Moreover, individuals who score higher in this trait 
may more diligently follow rubrics and identify more mistakes in their assigned papers.

In addition, two independent studies identified openness as the second largest correlation to academic achievement. Students high in openness are curious, imaginative, insightful, and tend to have wide intellectual interests (McCrae \& John, 1992). This relation is mediated by higher academic selfefficacy and the tendency to employ a deep learning strategy (Zhang \& Ziegler, 2016). Researchers have yet to identify a significant association between grade leniency and openness.

Agreeableness-characterized by trust, altruism, kindness, and compliance (McCrae \& John, 1992) is only somewhat related to academic achievement (Poropat, 2009; Richardson et al., 2012). However, this relation increases with each academic year (Farsides \& Woodfield, 2003). Agreeableness has also been linked to cooperation with instructors (Vermetten, Lodewijks, \& Vermunt, 2001) and higher attendance (Farsides \& Woodfield, 2003). As result of their desire to please others, agreeable graders tend to be more lenient (giving higher and less valid grades) to avoid upsetting their peers (Bernadin et al., 2009; Birjandi \& Syyari, 2016).

In contrast, extraversion-characterized by activeness, assertiveness, chattiness, outgoingness, plus the tendency to seek excitement (McCrae \& John, 1992) - is negatively related to academic achievement (Poropat, 2009; Richardson et al., 2012). Extraverted students are more likely to externalize academic responsibility - a component of academic entitlement related to poor grades (Bonaccio, Reeve, \& Lyerly, 2016). Although the relation between extraversion and grade leniency has not been investigated in an academic setting, research on rater leniency in the workplace can offer some insight. Cheng, Hui, and Cascio (2017) found extraversion to be related to higher rating leniency and more generous ratings in realtors' performance reviews conducted by coworkers; it may be that those higher in extraversion are more aware of the social repercussions of poor ratings.

Lastly, no significant relation has been found between neuroticism and either academic achievement or grade leniency (Poropat, 2009; Richardson et al., 2012). Perhaps because students high in neuroticism are anxious, impulsive, tense, irrational thinkers, and have low self-esteem (McCrae \& John, 1992), neuroticism is significantly related to self-handicapping (Ross et al., 2002), surface learning (Zhang, 2003), and low academic self-concept (Zhang \& Ziegler, 2016).

\section{Learning Orientation, Grade Orientation, Narcissism, and} Academic Entitlement

Aside from the five-factor model of personality, students' orientation and attitudes towards learning is tied to their academic achievement. Learning orientation is the approach to education as an opportunity for self-improvement and enlightenment, whereas grade orientation is the attitude that education is for obtaining high grades and positive evaluations (Eison, Pollio, \& Milton, 1983). Learning orientation is related to higher grades (Haris \& Haris, 1987), lower test anxiety, and higher satisfaction with courses ((Eison et al., 1983). These students also tend to have higher self-efficacy which is tied to improved performance (Phillips \& Gully, 1997). In contrast, grade orientation is related to the belief that ability is less malleable, which leads to lower self-efficacy and performance (Phillips \& Gully, 1997). Thus, grade orientation is often accompanied by an overwhelming pressure to succeed which can be debilitating when individuals high in this trait feel their goals are unattainable (Utman, 1997). Finally, grade orientation has been linked to poorer studying habits and higher academic entitlement which further decrease academic achievement (Vallade, Martin, \& Weber, 2014). 
The relation between learning orientation and grade leniency has yet to be explored; it can be argued that individuals high in learning orientation value education and learning experiences, which may lead to harsh marking on assignments that were not taken seriously. Moreover, learning orientation has been linked to higher grades and a better understanding of material (Haris \& Haris, 1987), which may lead to an ability to better judge the accuracy and merit of assignment content. This may in turn be related to lower grade leniency, as learning oriented individuals may more easily find mistakes.

Academic entitlement- the belief that one deserves academic success regardless of effort (Chowning \& Campbell, 2009)—is related to lower grades (Bonaccio et al., 2016), lower course self-efficacy, and more social network use (Boswell, 2012). Furthermore, academic entitlement is related to lower personal control and need for cognition (Chowning \& Campbell, 2009), as well as higher extrinsic motivation, achievement anxiety, and academic dishonesty (Greenberger et al., 2008). The relation between academic achievement and grade leniency has not yet been explored. Students higher in this trait may give more generous grades because of their expectation of high grades with little effort, however, this would only occur if this belief extends to other students.

Subclinical narcissism is a personality trait characterized by overconfidence, grandiosity, entitlement, arrogance, poor self-awareness, and selfobsession (MacDonald, 2014). Limited research has considered the relation between narcissism and academic achievement, though narcissism has been found to be related to entitled expectations (Turnipseed \& Cohen, 2015) and academic dishonesty (Brunell et al., 2011). Some studies have found a small positive relation between narcissism and academic achievement, perhaps because grades provide an opportunity for self-enhancement (Abe, 2014; Westerman et al., 2016). Furthermore, Wallace and Baumeister (2002) found individuals high in narcissism perform above average when a task is perceived either as challenging or as an opportunity to self-enhance; however, no difference in performance has been observed in other tasks. Therefore, narcissism may only have a positive relation with grades if the student views the assignment as an opportunity for self-enhancement. Although no research has been done directly on narcissism and grade or rater leniency, research by Westerman and colleagues (2016) suggests perceived difficulty of professors may be more dependent on the congruency of student and professor narcissism rather than the professor's narcissism levels; it follows that there may not be a direct relation between students' narcissism and their grade leniency.

\section{The Present Study}

The present study sought to identify how the big five personality traits (conscientiousness, openness, agreeableness, extraversion, and neuroticism), narcissism, academic entitlement, and both learning and grade orientation were related to grade leniency during an undergraduate peer review. Although research has identified conscientiousness, agreeableness, and extraversion as personality factors related to grade and rater leniency (Birjandi \& Syyari, 2016; Cheng, Hui, \& Cascio, 2017), various factors are left under-explored-more research is needed in academic settings. Based on research by Bonaccio et al. (2016), Birjandi and Syyari (2016), Haris and Haris (1987), and Poropat (2009), we hypothesized the following:

1. Agreeableness would positively predict grade leniency

2. Both conscientiousness and learning orientation would negatively predict grade leniency; and

3. Academic entitlement, conscientiousness, and learning orientation would be the significant predictors of academic success 


\section{Method}

\section{Participants}

Two Introduction to Psychology courses in the Fall 2017 semester at the University of Windsor were approached to participate in this study. Of the 300 undergraduates approached, $47(16 \%)$ elected to participate. They self-identified primarily as Caucasian (75\%), followed by African/American $(11 \%)$, Asian (9\%), Arabic (2\%), Indian (2\%), and mixed $(2 \%)$. The majority of participants identified as female $(85 \%)$ with a mean age of 21.04 years (SD $=4.45)$.

\section{Peer Review Process}

As part of their introductory class, all students completed a peer review assignment worth $10 \%$ of their final grade. The paper involved submission of both a 120-word maximum summary of an assigned article, and a 350-word maximum commentary (including 2 to 3 outside references). Students uploaded their assignments to a website that later anonymized papers and randomly assigned each one to six peers for grading according to a previously provided rubric (stipulating no student could grade their own assignment). Students were given one week to both grade their assigned papers using a 10-point scale (according to the detailed rubric provided; see Appendix A) and give feedback to justify the grades awarded. Their six grades and feedback were visible to students, however graders' identities remained anonymous.

Once the courses were complete and final grades submitted to the Registrar's office, students were sent a recruitment email with a brief description of the study and a link to an online survey. Four scales and a demographics questionnaire were administered through the online survey program Qualtrics, taking no more than 20 minutes to complete. As compensation for their time, participants were entered in a draw to receive one of four campus currency cards valued at $\$ 25$ each. All measures were scored according to their respective standardized procedures and merged with the peer review data for the respective participants.

\section{Measures}

In previous research, Grade Leniency was calculated by subtracting either an expert's grade (Birjandi \& Syyairi, 2016; Borman, Hough, \& Dunette, 1978) or an average grade as derived from peers (Cheng et al., 2017; Kane et al., 1995). As personality is hypothesized to significantly impact grading behaviour, we utilized this latter approach to prevent any personality bias from a single grader. So as to derive individual leniency scores, for each assignment the mean grade others gave that same assignment was subtracted from the grade the participant gave. For example, if a student gave a paper a score of 8 out of 10 while the remaining five graders awarded that same paper an average of 7 , then a +1 leniency scores was derived for that grader on that paper. The average of each participants' six leniency scores was calculated and then standardized. Negative grade leniency scores represented more stringent (belowaverage) marking whereas positive grade leniency scores represented more generous (above-average) marking. Furthermore, Average Grade Received was calculated as the mean grade a participant received from their peers on their peer review assignment.

Finally, to further investigate the relation between personality, grades, and grading behaviour, two variance measures were calculated. Variance in Grades Received was calculated as the variance of the six grades each student received from their peers, and Variance in Grades Given was calculated as the variance in the six grades one awarded the assignments they graded.

\section{Personality Measures}

Academic Entitlement was assessed using the Academic Entitlement Scale (Greenberger et al., 2008), a 15-item questionnaire that explores students' 
expectations of high grades despite minimal effort (e.g., "If I have attended most classes for a course, I deserve at least a grade of B"). Participants responded on a 6-point Likert scale with responses ranging from 1 (Strongly Disagree) to 6 (Strongly Agree). The mean response was calculated where higher scores represented greater academic entitlement. Greenberger and colleagues (2008) reported high internal consistency (Cronbach's alpha $=.87)$. Concurrent validity was established through significant moderate correlations to both the Psychological Entitlement and Exploitive Entitlement Scales, as well as a significant negative correlation to Work Orientation. We presently obtained a Cronbach's alpha of .86.

Narcissism was assessed using the 16-item version of the Narcissistic Personality Inventory (Ames, Rose, \& Anderson, 2006), a scale that measures subclinical narcissism through self-enhanced perceptions of behaviours and abilities. Participants were given pairs of statements to choose from including one narcissistic and one non-narcissistic response (e.g., "I am more capable than other people" or "There is a lot that I can learn from other people"). The total number of narcissistic responses selected from the pairs of statements divided by 16 was used as a summary score. Ames and colleagues (2006) found high retest reliability of .85 after 5 weeks and a Cronbach's alpha of .72. Concurrent validity was established through significant correlations with both narcissism and self-reported attractiveness rankings. We presently obtained a Cronbach's alpha of .74.

Learning Orientation and Grade Orientation were assessed using the 32-item scale (Eison et al., 1983, Version II) that reveals how important grades and learning are to students. The 16-item Learning Orientation Subscale assesses how much students value learning and enlightenment; 8 of these items measure academic attitudes (e.g., "I find the process of learning new material fun") using a 5-point Likert scale ranging from 1 (Strongly disagree) to 5 (Strongly agree) and the remaining 8 items measure observable behaviours (e.g., "I discuss interesting material that I've learned in class with my friends or family") using a 5-point scale ranging from 1 (Never) to 5 (Always). In contrast, the Grade Orientation Subscale consists of 16 questions that assess how important grades are to students; 8 items measure academic attitudes (e.g., "I think grades provide me a good goal to work toward") and the other 8 measure observable behaviours (e.g., "I will withdraw from an interesting class rather than risk getting a poor grade") with the same scoring as above. The mean score of all four subscales was calculated with higher scores representing higher levels of that orientation. Eison and colleagues (1983) reported good internal consistency (Cronbach's alphas ranged from .73 to .76). The following Cronbach's alphas were obtained: .75 (Learning Orientation Attitudes), .81 (Learning Orientation Behaviours), .71 (Grade Orientation Attitudes), and .78 (Grade Orientation Behaviours).

The Big Five Personality Traits were assessed through the Ten-item Personality Inventory (TIPI) (Gosling, Rentfrow, \& Swann, 2003), a short 10-item measure of conscientiousness, agreeableness, openness, extraversion, and emotional stability using a 7-point Likert scale with responses ranging from 1 (Disagree Strongly) to 7 (Agree Strongly). Each personality trait has two corresponding items and the average of these responses was used with higher scores representing higher levels of this trait. Gosling et al. (2003) found that over a period of 6 weeks, the TIPI had a retest reliability of .71 across the 5 traits. Concurrent validity was established through strong correlations to the Big Five Inventory (Gosling et al., 2003).

\section{Results}

To begin, Table 1 shows the means, standard deviations, and minimum and maximum values for all variables. We set our significance level at $\alpha=.05$ for all statistical tests. 
Table 1. Means, ranges, and standard deviations of personality measures and grading variables $(n=47)$

\begin{tabular}{lllll}
\hline Variable & Mean & Standard Deviation & Minimum & Maximum \\
\hline & & & & \\
\hline Grade Leniency & 0.18 & 1.58 & -2.71 & 4.80 \\
Average Grade Received & 7.72 & 1.34 & 2.25 & 9.67 \\
Academic Entitlement & 2.63 & 0.75 & 1.13 & 4.67 \\
Narcissism & 0.23 & 0.19 & 0.00 & 0.69 \\
Conscientiousness & 5.37 & 1.40 & 2.00 & 7.00 \\
Extraversion & 3.54 & 1.84 & 1.00 & 7.00 \\
Agreeableness & 4.83 & 1.28 & 2.00 & 7.00 \\
Openness & 5.19 & 1.04 & 2.50 & 7.00 \\
Emotional Stability & 4.03 & 1.53 & 1.00 & 6.50 \\
Learning Orientation Attitudes & 3.52 & 0.64 & 1.00 & 4.75 \\
Learning Orientation Behaviours & 2.42 & 0.73 & 1.25 & 4.13 \\
Learning Orientation Score & 2.97 & 0.53 & 1.94 & 4.38 \\
Grade Orientation Attitudes & 3.27 & 0.67 & 1.00 & 4.63 \\
Grade Orientation Behaviours & 2.07 & 0.74 & 1.00 & 4.00 \\
Grade Orientation Score & 2.67 & 0.59 & 1.50 & 4.13 \\
\hline
\end{tabular}

Table 2 shows the results of all the correlational analyses. The relation between grade leniency and personality was examined through correlations and stepwise regression analyses; all statistical assumptions were met. Learning orientation attitude scores were significantly related to grade leniency ( $\mathrm{r}$ $(45)=-0.32, \mathrm{p}=.028)$, where higher learning orientation attitude students offered less lenient grades. Similarly, grade leniency was marginally related to conscientiousness $(\mathrm{r}(45)=-0.27, \mathrm{p}=.063)$ and grade orientation attitude ( $\mathrm{r}(45)=-0.25$, $\mathrm{p}=.088$ ), where students higher in these traits also gave less lenient grades. Our final stepwise regression model explained $20 \%$ of the variance $(\mathrm{F}(2,44)=$ 5.43, $\mathrm{p}=.008)$, and included both learning orientation attitudes $(\beta=-.353, \mathrm{t}(44)=-2.60, \mathrm{p}=$ .013 , sr2 $=.12)$ and conscientiousness $(\beta=-.310, \mathrm{t}$ $(44)=-2.28, \mathrm{p}=.027, \mathrm{sr} 2=.09)$.

Moreover, four personality variables correlated significantly with the average grade received on peer review. The grade received was negatively related to academic entitlement $(\mathrm{r}(45)=-0.40, \mathrm{p}=.005)$, narcissism $(\mathrm{r}(45)=-0.32, \mathrm{p}=.028)$, and extraversion $(\mathrm{r}(45)=-0.29, \mathrm{p}=.048)$. The grade received was positively related to conscientiousness $(\mathrm{r}(45)=0.31$, $\mathrm{p}=.035)$. In sum, the grade on a paper was higher if the submitter felt less entitled and narcissistic but was more introverted and conscientious.

A stepwise regression analysis was performed with average grade received as criterion, having met all the assumptions after omitting a single outlier (standardized residual $=-3.84)$. The final model explained $39 \%$ of the variance $(\mathrm{F}(3,42)=8.86, \mathrm{p}<$ $.001)$ and included narcissism $(\beta=-.410, \mathrm{t}(42)=$ 3.31, $\mathrm{p}=.002, \mathrm{sr} 2=.16)$, academic entitlement $(\beta=$ $-.462, \mathrm{t}(42)=-3.32, \mathrm{p}=.002, \mathrm{sr} 2=.16)$, and grade orientation $(\beta=.313, \mathrm{t}(42)=2.28, \mathrm{p}=.028, \mathrm{sr} 2=$ .08). Lastly, we examined the relation between personality and the variance in both grades received and given. Variance in grades given was only marginally related to agreeableness $(\mathrm{r}(45)=-0.28, \mathrm{p}$ $=.059)$, wherein more agreeable students tended to be less variable (more consistent) in the grades they gave their peers. Additionally, variance in grades received was related negatively to agreeableness ( $r$ 
(45) $=-0.36, \mathrm{p}=.013)$, and positively to both openness $(\mathrm{r}(45)=0.29, \mathrm{p}=$

$.047)$ and narcissism $(r(45)=0.35, p=.015)$. In sum, students high in agreeableness and low in both narcissism and openness received more consistent grades.

Table 2. Correlations between all personality and peer review variables.

\begin{tabular}{|c|c|c|c|c|c|c|c|c|c|c|c|c|c|c|c|}
\hline & 1 & 2 & 3 & 4 & 5 & 6 & 7 & 8 & 9 & 10 & 11 & 12 & 13 & 14 & 15 \\
\hline 1 Grade Leniency & & & & & & & & & & & & & & & \\
\hline 2 Grade received & -0.189 & & & & & & & & & & & & & & \\
\hline 3 Grade received variance & 0.189 & -0.399 & & & & & & & & & & & & & \\
\hline 4 Academic entitlement & 0.195 & -0.402 & 0.220 & & & & & & & & & & & & \\
\hline 5 Narcissism & 0.047 & -0.320 & 0.352 & 0.204 & & & & & & & & & & & \\
\hline 6 Conscientiousness & -0.274 & 0.309 & -0.170 & -0.255 & -0.265 & & & & & & & & & & \\
\hline 7 Agreeableness & -0.018 & 0.153 & -0.360 & -0.016 & -0.303 & -0.082 & & & & & & & & & \\
\hline 8 Extroversion & 0.029 & -0.291 & 0.243 & 0.271 & 0.611 & -0.369 & -0.073 & & & & & & & & \\
\hline 9 Openness & -0.191 & -0.214 & 0.291 & 0.015 & 0.340 & 0.006 & 0.062 & 0.403 & & & & & & & \\
\hline 10 Neuroticism & -0.060 & -0.117 & -0.151 & -0.009 & -0.033 & 0.257 & 0.160 & 0.155 & 0.054 & & & & & & \\
\hline $11 \mathrm{LO}$ attitude & -0.321 & -0.025 & 0.009 & 0.081 & 0.065 & -0.102 & -0.142 & 0.206 & 0.200 & -0.080 & & & & & \\
\hline $12 \mathrm{LO}$ behaviour & -0.041 & -0.268 & 0.028 & -0.085 & 0.251 & 0.000 & -0.030 & 0.169 & 0.117 & 0.195 & 0.177 & & & & \\
\hline $13 \mathrm{LO}$ total score & -0.223 & -0.230 & 0.024 & -0.010 & 0.216 & -0.061 & -0.106 & 0.243 & 0.204 & 0.087 & 0.726 & 0.805 & & & \\
\hline $14 \mathrm{GO}$ attitude & -0.252 & 0.024 & 0.057 & 0.470 & 0.007 & 0.012 & 0.110 & 0.097 & 0.202 & 0.045 & -0.096 & -0.239 & -0.110 & & \\
\hline $15 \mathrm{GO}$ behaviour & 0.140 & -0.013 & 0.197 & 0.321 & 0.217 & -0.267 & 0.176 & 0.062 & -0.110 & -0.203 & -0.296 & -0.122 & -0.264 & 0.377 & \\
\hline $16 \mathrm{GO}$ total score & -0.057 & 0.005 & 0.159 & 0.473 & 0.143 & -0.161 & 0.174 & 0.098 & 0.048 & -0.103 & -0.133 & -0.213 & -0.229 & 0.812 & 0.847 \\
\hline
\end{tabular}

\section{Discussion}

This study investigated the relation between personality, grades, and grading behaviours, and is the first to consider the relation between grade leniency and narcissism, grade orientation, learning orientation, and academic entitlement. Several significant findings were uncovered, many of which are consistent with past research; however, some findings were unexpected and warrant further exploration.

We first hypothesized that agreeableness would be the strongest predictor of grade leniency. Consistent with previous research (Bernadin et al., 2009; Birjandi \& Syyari, 2016), it was expected that the desire to please others would result in more lenient grades; however, agreeableness was not related to grade leniency. There was a marginally significant relation between agreeableness and variance in grades given, wherein more agreeable students tended to award more consistent grades. It appears that rather than giving higher grades to please peers, students higher in agreeableness gave grades in a small interval that were not noticeably high or low. This may be to avoid upsetting their professor with grades that are too high or their peers with grades that are too low.

Secondly, we hypothesized that both conscientiousness and learning orientation would be related to lower grade leniency; this was supported. Consistent with past research (Bernadin et al., 2009; Birjandi \& Syyari, 2016), conscientiousness was found to be related to less lenient and more accurate grades. This may be because those high is this trait are diligent, and detail orientated (McCrae \& John, 1992), which may lead to graders who follow the rubric carefully and notice all the mistakes in 
assignments. Moreover, conscientiousness has been linked to higher academic achievement and deeper learning (Zhang \& Ziegler, 2016). As a result, individuals higher in this trait may have a deeper understanding of the material they are grading and therefore better able to judge the accuracy of the assignment content.

In contrast, past research has yet to uncover an association between learning orientation attitudes and grade leniency. Like conscientiousness, learning orientation has been linked to a better understanding of material (Haris \& Haris, 1987), which may similarly lead to an ability to better judge accuracy and merit of the assignment content. However, learning orientation attitudes specifically involve valuing education and learning opportunities (Eison et al., 1983). This trait may lead students to be more upset by peers who do not take the assignment seriously and as a result mark more harshly.

In addition to learning orientation attitudes and conscientiousness, a trend was found wherein students higher in grade orientation attitudes tended to give less lenient grades. Grade orientated students often want to achieve the highest marks with the lowest efforts (Eison et al., 1983) and tend to be more concerned with their relative standing to their peers (Utman, 1997). They often experience intense pressure to achieve their goals which prove detrimental (Utman, 1997). As a result, students higher in grade orientation attitudes may mark less leniently in order to reduce competition and have more favorable relative standing. Further research is needed to explore these possibilities.

Finally, we hypothesized that the significant predictors of academic achievement would be academic entitlement, conscientiousness, and learning orientation; this was partially supported wherein academic entitlement was related to lower grades on the peer reviewed assignments (Bonaccio et al., 2016). Past research has shown students high in this trait receive lower grades because they expect high grades with minimal effort, have less personal control, and experience a reduced need for cognition (Chowning \& Campbell, 2009). Moreover, academic entitlement is related to a lower self-efficacy (Boswell, 2012) and higher achievement anxiety (Greenberger et al., 2008) which create further barriers to academic success.

As hypothesized, conscientiousness was related to higher grades on the peer review. This relation is well documented due to the many benefits of conscientiousness for student success including selfdiscipline, diligence, and achievement orientation (McCrae \& John, 1992). These students also have higher academic self-efficacy (Zhang \& Ziegler, 2016), better metacognition, excellent time management skills, and superior effort regulation (McCrae \& John, 1992). Indeed, comprehensive meta-analyses often cite conscientiousness as a powerful predictor of academic achievement (Poropat, 2009; Richardson et al., 2012).

Contrary to expectations, learning orientation was not significantly related to grades received, possibly because the relationship between learning orientation and academic achievement is mediated by perceived task difficulty (Utman, 1997). Thus, if students did not perceive the peer review assignment as difficult, then any advantage of learning orientation would not apply. A stepwise regression identified narcissism, academic entitlement, and grade orientation as significant predictors of academic achievement. Narcissism had a moderate negative relationship with grades received, where students higher in narcissism received lower grades on the peer reviewed assignments. This was unexpected since past research identified a positive relation between narcissism and grades received (Abe, 2014; Westerman et al., 2016). However, the anonymity embedded in the peer review reduces the opportunity for self-enhancement, which may have in turn reduced performance because self-enhancement is the main motivator for those high in narcissism (Wallace \& Baumeister, 2002). Moreover, narcissism is related to impulsivity and reduced self-regulation which both render it difficult to resist temptation of 
distractions long enough to write academic papers (Vazie \& Funder, 2006). Moreover, Robins and Beer (2001) found academic engagement levels of narcissistic students declined in an effort to selfprotect against inflated grade expectations. Thus, participants high in narcissism may have begun to disengage from school as their first semester in university progressed and they experienced the typical grade drop. More research is needed to explore the conditions in which narcissism is either beneficial or harmful to grades.

Contrary to expectations, grade orientation was a significant positive predictor of grades received. Grade orientation is typically related to poor academic achievement because the pressure to obtain high grades can be debilitating when students fear their academic goals are unattainable (Utman, 1997). However, if the peer review assignment was viewed as a manageable task, then this fear may not have interfered with their performance. Moreover, students high in grade orientation tend to see education as an opportunity for high grades and positive evaluations (Eison et al., 1983). This high motivation for academic success may lead students high in this trait to follow the rubric more diligently and ensure all necessary components of the assignments are present. Future studies should investigate the possible advantages of grade orientation and explore circumstances in which it may be better than learning orientation.

In addition to academic entitlement, conscientiousness, and narcissism, grades received was related to extraversion where higher levels implied lower grades. This relation is consistent with past research (Poropat, 2009; Richardson et al., 2012), as extraversion is related to externalized academic responsibility - a component of academic entitlement related to poor grades (Bonaccio et al., 2016). Extraverted students are also more social (McCrae \& John, 1992), which may interfere with finding sufficient time to work on assignments.

When we explored the relation between personality and variance in grades received, several variables were significant, including narcissism. We suspect this occurred because the narcissists' personality may surface in both their writing style and tone of the written assignment, more precisely through overconfidence, self-obsession, grandiosity, arrogance, and entitlement (MacDonald, 2014). If these traits are clear in these students' assignments, some graders may give lower grades out of dislike for this type of individual. In contrast, more objective graders will mark according to the rubric without allowing their personal feelings to interfere with their grading which may result in higher grades. In previous studies, essays have been accurately classified by big five personality factors based upon writing features such as word choice, punctuation, topic choice, and pronoun usage (Mairesse et al., 2007; Li \& Chignell, 2010). Although the detectability of narcissism in writing has not yet been identified, if these traits are evident in the written assignments, this may explain the variance in grades received, however, future research is needed to further explore this relation.

In contrast, agreeableness was found to have a significant negative relation with variance in grades received, where students higher in agreeablenesscharacterized by trust, altruism, kindness, compliance, and the desire to please others (McCrae \& John, 1992) — had little variability in the grades their peers gave them. Students high in agreeableness may choose less controversial topics to avoid upsetting readers and their kindness may be evident in their writing style. Mairesse and colleagues (2007) support this explanation with the finding that individuals higher in agreeableness tend to avoid negations and negative emotions in their writing. If this is the case in the present study, the subjective influence on grading should be minimized leading to less variability in grades received. Future research is needed to explore this possibility.

Lastly, openness was found to have a significant positive relation with variance in grades received where students higher in openness — characterized as curious, imaginative, insightful, with a wide array of 
intellectual interests (McCrae \& John, 1992)—had more variability in the grades their peers gave them. Moreover, openness is related to more novel idea generation (Madrid \& Patterson, 2014) which could lead to more novel arguments in papers and controversial topics. This explanation is supported with Mairesses and colleagues (2007) finding that individuals higher in openness are more likely to discuss religion and metaphysical issues in freewriting. Students may react differently to the more original and controversial arguments, creating a variation in grades related to the graders' acceptance and appreciation of this novelty.

There were some notable limitations to this study. Firstly, there was only a sixteen percent response rate resulting in an underpowered sample. Secondly, although this study focused on personality's relation to grades and grading behaviours, there are many factors that may have influenced grading behaviours that were not examined. We did not have access to how long students spent grading, the number of times papers were visited, and the order they graded the papers in. These timing factors may have influenced the grades one received or variability in the grades one gave. Thirdly, factors such as the time of day the papers were graded or the student's emotional state while grading were not considered. Lastly, prior grading experience was not assessed which may have influenced grade leniency.

To conclude, grade leniency is a factor affecting the accuracy of grades in peer reviews and professional grading alike. This variable is predicted by learning orientation attitudes and conscientiousness. Moreover, the variance in students' grades is related to their levels of openness, agreeableness, and narcissism. The influence of personality on grading is substantial and peer-reviews have shown this influence can be reduced when many graders' ratings are combined. Due to a large variance in grades assigned by the instructor to the same assignment (Brookhart et al. 2016), should multiple graders perspectives be combined to improve grading accuracy? This question, along with the influence of personality on grading behaviours in instructors requires further research and possible safeguards should be investigated.

\section{References}

Abe, S. (2014). How narcissistic students behave in junior high school? Personality and Individual Differences, 60(Supplement), S58. https://doi.org/10.1016/j.paid.2013.07.248

Ames, D. R., Rose, P., \& Anderson, C. P. (2006). The NPI-16 as a short measure of narcissism. Journal of Research in Personality, 40(4), 440-450. doi:10.1016/j.jrp.2005.03.002

Bernadin, H.J., Tyler, C.L., \& Villanova, P. (2009). Rating level and accuracy as a function of rater personality. International Journal of Selection and Assessment, 17(3), 300-310.

Birjandi, P. \& Siyyari, M. (2016). Agreeableness and conscientiousness as predictors of university students' self/peer-assessment rating error. Irish Educational Studies, 35(1), 117-135. doi:10.1080/03323315.2016.1147973

Bidjerano, T., \& Dai, D.Y. (2007). The relationship between the big-five model of personality and self-regulated learning strategies. Learning and Individual Differences, 17(1), 69-81. doi:10.1016/j.lindif.2007.02.001

Bloxham, S. \& West, A. (2004). Understanding the rules of the game: Marking peer assessments as a medium for developing students' conceptions of assessment. Assessment \& Evaluation in Higher Education, 29(6), 721733. doi:10.1080/0260293042000227254

Boase-Jelinek, D., Parker, J., \& Herrington, J. (2013). Student reflection and learning through peer reviews. Issues in Educational Research, 23(2), 119-131. Retrieved from http://www.iier.org.au/iier23/boasejelinek.html

Bonaccio, S., Reeve, C.L., \& Lyerly, J. (2016). Academic entitlement: Its personality and 
general mental ability correlates, and academic consequences. Personality of Individual Differences, 102, 211-216. https://doi.org/10.1016/j.paid.2016.07.012

Borman, W.C., Hough, L.M., \& Dunnette, M.D. (Jul 1978). Performance ratings: An investigation of reliability, accuracy, and relationships between individual differences and rater error. Retrieved from http://www.dtic.mil/docs/citations/ADA 061149

Bostock, S. (2006). Student peer assessment. [viewed 21 Feb 2018]. Retrieved from http://www.reading.ac.uk/web/files/engag einassessment/student_peer_assessment__stephen_bostock.pdf

Boswell, S. (2012). "I deserve success.": Academic entitlement attitudes and their relationships with course self-efficacy, social networking, and demographics. Social Psychology of Education, 15(13), 353-365. doi:10.1008/s11218-012-9184-4

Brookhart, S. M., Guskey, T. R., Bowers, A. J., McMillan, J. H., Smith, J. K., Smith, L. F., . . . Welsh, M. E. (2016). A century of grading research. Review of Educational Research, 86(4), 803-848. doi:10.3102/0034654316672069

Brunell, A. B., Staats, S., Barden, J., \& Hupp, J. M. (2011). Narcissism and academic dishonesty: The exhibitionism dimension and the lack of guilt. Personality and Individual Differences, 50(3), 323-328. Doi: 10.1016/j.paid.2010.10.006

Cheng, K.H.C., Hui, C.H., \& Cascio, W.F. (2017). Leniency bias in performance ratings: The big-five correlates. Frontiers in Psychology, 8:251. doi:10.3389/fpsyg.2017.00521

Chowning, K., \& Campbell, N.J. (2009). Development and validation of a measure of academic entitlement: Individual differences in students' externalized responsibility and entitled expectations. Journal of Educational Psychology, 101(4), 982-997. doi:10.1037/a0016351
Eison, J. A., Pollio, H. R., \& Milton, O. (1983). Manual for use with LOGO-II. Theory and Practice in Teacher Education Publications and Other Works. Retrieved from http://trace.tennessee.edu/utk_theopubs/ 2

Farsides, T., \& Woodfield, R. (2003). Individual differences and undergraduate academic success: the roles of personality, intelligence, and application. Personality and Individual Differences, 34(7), 1225-1243. https:// doi.org/10.1016/S01918869(02)00111-3

Gosling, S. D., Rentfrow, P. J., \& Swann, W. B. (2003). A very brief measure of the Big-Five personality domains. Journal of Research in Personality, 37(6), 504-528. doi:10.1016/S0092-6566(03)00046-1

Greenberger, E., Lessard, J., Chen, C., \& Farruggia, S. P. (2008). Self-entitled college students: Contributions of personality, parenting, and motivational factors. J Youth Adolescence, 37(10), 1193-204. doi:10.1007/s10964-0089284-9

Guilford, J.P. (1954). Psychometric Methods. New York, NY: McGraw-Hill.

Harris, C.M. \& Harris, J.S. (1987). Learning orientation and academic achievement. Retrieved from https://eric.ed.gov/?id=ED283107

Joordens, S., Paré, D., \& Collimore, L-M. (2014). Taking Learning Outcomes to the Gym: An Assignment-Based Approach to Developing and Assessing Learning Outcomes. Toronto: Higher Education Quality Council of Ontario.

Kane, J.S., Bernadin, H.J., Villanova, P., \& Peyrefitte, J. (1995). Stability of rater leniency: Three studies. Academy of Management Journal, 36(4), 1036-1051.

Li, H., Xiong, Y., Zang, X., Kornhaber, M.L., Lyu, Y., Chung, K.S., \& Suen, H.K. (2015). Peer assessment in the digital age: A meta-analysis comparing peer and teacher ratings. Assesment \& Evaluation in Higher 
Education, $\quad 41(2), \quad 245-264$. doi:10.1080/02602938.2014.999746

Li, J., \& Chignell, M. (2010). Birds of a feather: How personality influences blog writing and reading. International Journal of HumanComputer Studies, 68(9), 589-602. https:// doi.org/10.1016/j.ijhcs.2010.04.00 1

MacDonald, P. (2014). Narcissism in the modern world. Psychodynamic Practice, 20(2), 144 153. doi:10.1080/14753634.2014.894225

Madrid, H.P. \& Patterson, M.G. (2016). Creativity as a joint function between openness to experience, need for cognition and organizational fairness. Learning and Individual Differences, 51(Complete), 409416. doi:10.1016/j.lindif.2015.07.010

McCrae, R.R., \& John, O.P. (1992). An introduction to the five-factor model and its applications. Journal of Personality, 60(2), 175-215. doi:10.111/j.1467-6494.1992.tb00970

Mairesse,F., Walker, M. A., Mehl, M. R., \& Moore, R. K. (2007). Using linguistic cues for the automatic recognition of personality in conversation and text. Journal of Artificial Intelligence Research, 30, 457-500. https://doi.org/10.1613/jair.2349

Paré, D. E., \& Joordens, S. (2008). Peering into large lectures: Examining peer and expert mark agreement using peerScholar, an online peer assessment tool. Journal of Computer Assisted Learning, 24, 526-540.

Phillips, J. M., \& Gully, S. M. (1997). Role of goal orientation, ability, need achievement, and locus of control in the self-efficacy and goalsetting process. Journal of Applied Psychology, 82(5), 792-802. doi: 10.1037/0021-9010.85.5.792

Poropat, A. E. (2009). A meta-analysis of the fivefactor model of personality and academic performance. Psychological Bulletin, 135, 322. http://dx.doi.org/10.1037/a0014996.

Richardson,M., Abraham, C., \& Bond, R. (2012). Psychological correlates of university 10(2), 154-165. doi: 10.1207/s15327957pspr1002_4 students' academic performance: A systematic review and meta-analysis. Psychological Bulletin, 138, 353-387. http://dx.doi.org/10.1037/a0026838.

Robins, R., \& Beer, J. S. (2001). Positive illusions about the self: Short-term benefits and longterm costs. Journal of Personality and Social Psychology, 80(2), 340-52. doi: 10.1037/0022-3514.80.2.340

Ross, S.R., Canada, K.E., \& Rausch, M.K. (2002). Self-handicapping and the five factor model of personality: Mediation between neuroticism and conscientiousness. Personality and Individual Differences, 32(7), 1173-1184. https://doi.org/10.1016/S01918869(01)00079-4

Sims, G. K. (1989). Student peer review in the classroom: A teaching and grading tool. Journal of Agronomic Education, 18(2), 105-108. Retrieved from https://www.agronomy.org/files/publicati ons/jnrlse/pdfs/jnr018/018-02-0105.pdf

Turnipseed, D. L., \& Cohen, S. R. (2015). Academic entitlement and socially aversive personalities: Does the dark triad predict academic entitlement? Personality and Individual Differences, 82(Complete), 7275. doi: $10.1016 /$ j.paid.2015.03.003

Utman, C. H. (1997). Performance effects of motivational state: A meta-analysis. Personality and Social Psychology Review, 1(2), 170-182. doi: 10.1207/s15327957pspr0102_4

Vallade, J.I., Martin, M.M., \& Weber, K. (2014). Academic entitlement, grade orientation, and classroom justice as predictors of instructional beliefs and learning outcomes. Communication Quarterly, 62(5), 497-517. doi:10.1080/01463373.2014.949386

Vazire, S., \& Funder, D. C. (2006). Impulsivity and the self-defeating behavior of narcissists. Personality and Social Psychology Review, 
Wallace, H.M., \& \& Baumeister, R.F. (2002). The performance of narcissists rises and falls with perceived opportunity for glory. Journal of Personality and Social Psychology, 82(5), 819-834. doi:10.1037/0022-3514.82.5.819

Westerman, J.W., Whitaker, B.G., Bergman, J.Z., Bergman, S.M., \& Daly, J.P. (2016). Faculty narcissism and student outcomes in business higher education: A student-faculty fit analysis. International Journal of Management Education, 14(2), 63-73. doi:10.1016/j.ijme.2016.02.001

Vermetten, Y.J., Lodewijks, H.G., \& Vermunt, J.D. (2001). The role of personality traits and goal

\section{Biographies}

Jenessa Shaw is an undergraduate student in Psychology at the University of Windsor. Her research interests include personality, body image, and self-compassion.

\section{Appendix A: Grading Rubric}

Abstract

Maximum 120-word summary (2 points) should include an opening and concluding sentence and all the relevant points made by the author - no citations or personal views should be included.

\section{Commentary}

Clear statement of the issues being addressed (2.5 points)

Appropriate sources used/integrated (1 point) Includes opening and concluding paragraphs $(.5$ point) orientations in strategy use. Contemporary Educational Psychology, 26(2), 149-170. https://doi.org/10.1006/ceps.1999.1042

Zhang, J. \& Ziegler, M. (2016). How do the big five influence scholastic performance? A big five-narrow traits model or a double mediation model. Learning and Individual Differences, $\quad 50, \quad 93-102$. https://doi.org/10.1016/j.lindif.2016.07.01 1

Zhang, L. F. (2003). Does the big five predict learning approaches? Personality and Individual Differences, 34, 1431-1446. http://dx.doi.org/10.1016/s01918869(02)00125-3

Ken Cramer is a Professor in Psychology at the University of Windsor specializing in the analysis of big data, including personality, education, and social psychology.

\section{In General}

Follows proper in-text citation and references (1 point)

Well-written and easy to follow (2 points)

Free of spelling and grammatical errors (1 point)

Total: 10 points

Note: These are not "all or nothing" grading allotments. Rather, they refer to the maximum available for each category. Spelling and grammar errors should be deducted at 0.25 points for each example of the error (i.e., do not deduct repeatedly for the same mistake). If sources such as Wikipedia are used, all points for sources (2) should be deducted. 